\title{
Interglacial ice extents of the Greenland ice sheet
}

Anders E. Carlson ${ }^{1}$ and Nicolaj K. Larsen ${ }^{2,3}$

The Greenland ice sheet has the capacity to raise sea level by $\sim 7.4 \mathrm{~m}$. Current terrestrial and marine data suggest that the ice sheet has usually been smaller than present during interglacial periods, showing a high sensitivity to current regional climate warming.

The Greenland ice sheet is the last surviving ice sheet of what was the order-of-magnitude larger extent of North Hemisphere ice sheets at the last glacial maximum about 21,000 years ago. As such, its responses to ongoing and future global warming represents a major concern regarding its impact on global sea level. In the last decade, the application of ${ }^{10} \mathrm{Be}$ exposure dating along with "threshold" lakes dated by ${ }^{14} \mathrm{C}$ now constrain the timing of when the Greenland ice sheet retreated to a smaller-than-present extent in the Holocene. Likewise, radiogenic isotopic tracers of silt-size particles combined with ice-rafted debris and subglacial bedrock cosmogenic isotopic concentration can provide evidence of how small the Greenland ice sheet may have been in prior interglacial periods. These data can provide important constraints on the sensitivity of the Greenland ice sheet to paleoclimates similar to, or warmer than, present.

\section{The Holocene}

The last deglaciation leading into the Holocene is characterized by abrupt climate changes recorded in Greenland ice cores. However, evidence for any response of Greenland ice-sheet margins on land is restricted mainly to the southernmost, westernmost and easternmost edges of Greenland; other terrestrial retreat of the Greenland ice sheet occurred during the Holocene (e.g. Young et al. 2013; Carlson et al. 2014; Larsen et al. 2015, 2018; Winsor et al. 2015; Young and Briner 2015; Sinclair et al. 2016; Reusche et al. 2018). This means that at an extended state on the continental shelf, the Greenland ice sheet appears to have been relatively stable and capable of surviving 10,000 years of deglacial warming before retreating to its current and then smaller-than-present extent.

The application of ${ }^{10} \mathrm{Be}$ exposure dating in a number of fjord transects (Fig. 1) has demonstrated that the deglaciation from the coast to the present ice margin occurred in most places within 500-1000 yr during the early Holocene (e.g. Winsor et al. 2015; Young and Briner 2015; Sinclair et al. 2016; Larsen et al. 2018). These yield retreat rates of 50-100 $\mathrm{m} \mathrm{yr}^{-1}$, which are similar to, or higher than, retreat rates observed at even the most sensitive glaciers today (Winsor et al. 2015). In west and southwest Greenland, the ice-sheet retreat halted during the early Holocene in response to the $\sim 9.3 \mathrm{kyr} \mathrm{BP}$ and $8.2 \mathrm{kyr} \mathrm{BP}$ cold events (e.g. Young et al. 2013; Winsor et al. 2015). Elsewhere in Greenland, evidence of early Holocene stillstands is lacking - not necessarily because they did not occur, but because late-Holocene advance may have overridden moraines from these stillstands (Carlson et al. 2014; Larsen et al. 2015, 2018; Sinclair et al. 2016; Reusche et al. 2018).

Cosmogenic ages on boulders next to modern ice margins (Fig. 1) and threshold lakes (Fig. 2), and radiocarbon dating on organic remains in historical moraines have been used to constrain periods with smaller-than-present ice extent (e.g. Carlson et al. 2014; Larsen et al. 2015; Young and Briner 2015). These records show that ice had retreated inland of its present extent during the Holocene thermal maximum $\sim 8-5$ kyr BP. This minimum ice extent was followed by a late-Holocene advance that culminated during the early 1900 s with the formation of pronounced Little Ice Age moraines in most parts of Greenland (Kjeldsen et al. 2015). However, ${ }^{10} \mathrm{Be}$ dating of moraines outside Little Ice Age moraines has shown that the

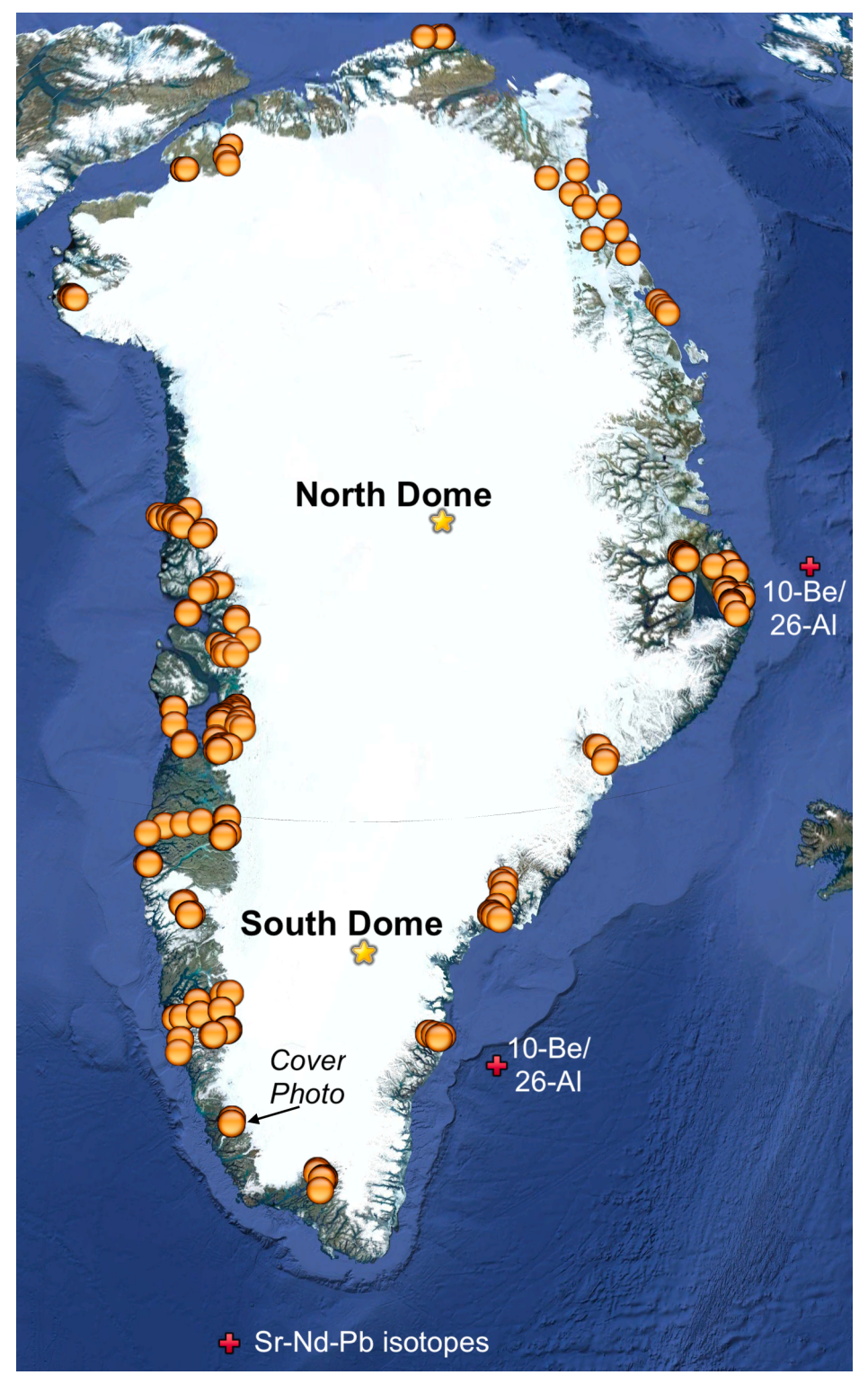

Figure 1: Location of ${ }^{10} \mathrm{Be}$ ages (yellow circles), basal ice and bedrock samples (stars), and marine sediment cores (red crosses) constraining Greenland ice-sheet paleo history. Location of issue cover photo from Nigerdlikasik Bræ denoted by arrow. 


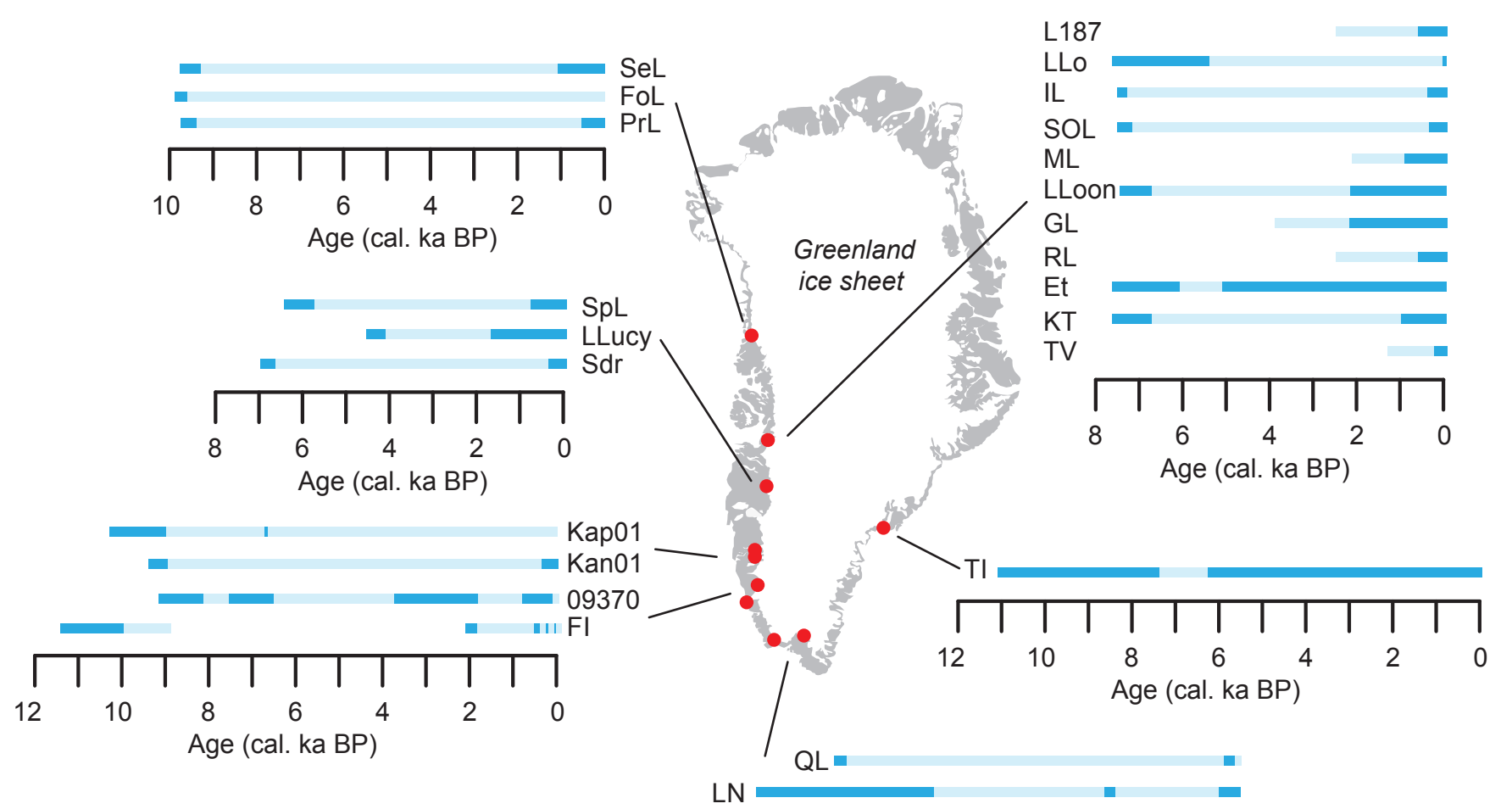

Figure 2: Examples of Holocene constraints on when the Greenland ice sheet was smaller than present based on proglacial threshold lakes (Young and Briner 2015; Larsen et al. 2015 and reference therein). Dark bars indicate that the ice margin is close to the lake and similar to the modern extent; light bars indicate ice-margin retreat out of the lake drainage basin and a smaller-than-present ice extent.

ice extent was larger prior to the Little Ice Age in southernmost (Winsor et al. 2014) and northwestern Greenland (Reusche et al. 2018). These records indicate that for much of the last 10,000 years the Greenland ice sheet was at a more retracted extent than it was in the industrial era.

\section{Prior interglacial periods}

The last interglacial period, 128-116 kyr BP, was an interval generally denoted as warmer than the peak Holocene due to greater precession forcing. Far-field sea-level indicators suggest that global mean sea level was 6-9 $\mathrm{m}$ above present, indicating that the global cryosphere was smaller than present. Marine sediment provenance records can constrain ice-sheet location on a given Greenland terrain (Colville et al. 2011). The dating of basal ice by the accumulation of radionuclide gases emitted from the underlying ground provides another means of reconstructing the Greenland ice sheet extent (Yau et al. 2016). The marine provenance records show that the southern Greenland ice dome survived through the last interglacial period (Fig. 1; Colville et al. 2011). The age of basal ice for the southern and northern Greenland domes is much older than the last interglacial (Fig. 1; Yau et al. 2016), in agreement with the marine records. These records suggest that the Greenland ice sheet only contributed less than $2.5 \mathrm{~m}$ ( $35 \%$ of the modern ice-sheet volume; Colville et al. 2011) to the last interglacial sea-level highstand.

Prior to the last interglacial period, marine sediment provenance evidence indicates that the southern Greenland ice sheet nearly completely deglaciated during marine isotope stage $11 \sim 400 \mathrm{kyr} \mathrm{BP}$ (Reyes et al. 2014). This agrees well with the $\sim 400 \mathrm{kyr} B P$ age of basal ice and sediment from the south Greenland ice dome (Fig. 1; Yau et al. 2016).
With a basal ice age of $1000 \mathrm{kyr}$ BP for the north Greenland ice dome (Fig. 1; Yau et al. 2016), these records suggest up to $6 \mathrm{~m}$ of sea-level rise coming from the Greenland ice sheet during marine isotope stage 11, accounting for the low end of global mean sealevel estimates for this interglacial period (Reyes et al. 2014).

On a longer timescale, marine and sub-ice cosmogenic records appear to be contradictory. For east Greenland, ice-rafted debris has been continuously deposited over the last three million years. The accumulation of ${ }^{10} \mathrm{Be}$ and ${ }^{26} \mathrm{Al}$ in this ice-rafted debris suggests the general persistence of the north Greenland ice dome in east Greenland over this time period with only short-lived periods of ice retreat and bedrock exposure (Fig. 1; Bierman et al. 2016). This would agree with the basal ice age of north Greenland ice dome of $1000 \mathrm{kyr} B P$, suggesting a stable north Greenland ice dome over the latter part of the Quaternary (Yau et al. 2016). Conversely, the accumulation of ${ }^{10} \mathrm{Be}$ and ${ }^{26} \mathrm{Al}$ in the bedrock underlying the north Greenland ice dome could indicate multiple intervals of exposure during the Quaternary (Fig. 1; Schaefer et al. 2016), which would imply a more dynamic ice dome than can be inferred from the marine ${ }^{10} \mathrm{Be}$ and ${ }^{26} \mathrm{Al}$ records (Bierman et al. 2016) and basal ice ages (Yau et al. 2016). However, the eastern mountains of Greenland are one of the last places to deglaciate in Greenland ice-sheet models (e.g. Schaefer et al. 2016), suggesting that the two ${ }^{10} \mathrm{Be}$ and ${ }^{26} \mathrm{Al}$ records may not be in conflict. Nevertheless, it is difficult to rectify the $\sim 1,000 \mathrm{kyr} B \mathrm{~B}$ age of the north Greenland ice dome basal ice with the accumulation of ${ }^{10} \mathrm{Be}$ and ${ }^{26} \mathrm{Al}$ in the underlying bedrock. The application of a third, shorterlived cosmogenic isotope from the bedrock, like ${ }^{36} \mathrm{Cl}$, could help in resolving the potential conflict between these two records.

\section{Summary}

The records discussed above demonstrate that the Greenland ice sheet has responded dramatically to past climate warming of only a few degrees Celsius or less above pre-industrial levels - warming levels we have already met or will meet in the next few decades. We can consequently conclude that we have reached, or will shortly reach, a climate state where the modern Greenland ice sheet is no longer stable (Carlson et al. 2014; Reyes et al. 2014).

\section{AFFILIATIONS}

${ }^{1}$ College of Earth, Ocean, and Atmospheric Sciences, Oregon State University, Corvallis, USA ${ }^{2}$ Department of Geoscience, Aarhus University, Denmark

${ }^{3}$ Centre for GeoGenetics, Natural History Museum of Denmark, University of Copenhagen, Denmark

\section{CONTACT}

Anders E. Carlson: acarlson@coas.oregonstate.edu REFERENCES

Bierman P et al. (2016) Nature 540: 256-260 Carlson AC et al. (2014) Geophys Res Lett 41: 5514-5521 Colville EJ et al. (2011) Science 333: 620-623 Kjeldsen KK et al. (2015) Nature 528: 396-400 Larsen NK et al. (2015) Geology 43: 291-294 Larsen NK et al. (2018) Nature Commun 9: 1872 Reusche MM et al. (2018) Geophys Res Lett 45: 7028-7039 Reyes AV et al. (2014) Nature 510: 525-528 Schaefer JM et al. (2016) Nature 540: 252-255 Sinclair G et al. (2016) Quat Sci Rev 145: 243-258 Winsor K et al. (2014) Quat Sci Rev 98: 135-143 Winsor K et al. (2015) Earth Planet Sci Lett 426: 1-12 Yau AM et al. (2016) Earth Planet Sci Lett 451: 1-9 Young NE, Briner JP (2015) Quat Sci Rev 114: 1-17 Young NE et al. (2013) Quat Sci Rev 60: 76-90 